\title{
Computed tomography morphometric analysis for C-1 posterior arch crossing screw placement in the pediatric cervical spine
}

\author{
Guang-Heng Xiang, MD, Chong Wang, MD, Chao Lou, MD, Ming-Qiao Fang, MD, \\ Nai-Feng Tian, MD, and Hua-Zi Xu, MD \\ Zhejiang Spine Research Center, Department of Orthopaedic Surgery, Second Affiliated Hospital of Wenzhou Medical University, \\ Wenzhou, Zhejiang, China
}

OBJECT The goal of this study was to evaluate the feasibility of the C-1 posterior arch crossing screw fixation technique in the pediatric age group.

METHODS One hundred twenty-three pediatric patients were divided into 6 age groups. Computed tomography morphometric analysis of the C-1 posterior arch was performed. Measurements included height, width, and length. Statistical analysis was performed using the Student t-test and linear regression analysis.

RESULTS The mean measurement of the posterior arch was height $(6.35 \pm 1.80 \mathrm{~mm})$, width (Width 1: $4.48 \pm 1.25 \mathrm{~mm}$; Width 2: $4.42 \pm 0.68 \mathrm{~mm}$; Width 3: $4.42 \pm 0.50 \mathrm{~mm})$, and length $(14.48 \pm 1.67 \mathrm{~mm})$. Seven $(6.93 \%)$ of the $101 \mathrm{children}$ in Groups $1-4$ and $13(59.1 \%)$ of the 22 children in Groups 5 and 6 could safely accommodate placement of C-1 posterior arch crossing screws.

CONCLUSIONS This investigation found that a C-1 posterior arch crossing screw was feasible in this group of Chinese pediatric patients, particularly in those 13 years and older. Preoperative thin-cut CT is essential for identifying children in whom this technique is applicable and for planning screw placement.

http://thejns.org/doi/abs/10.3171/2014.11.PEDS14191

KEY WORDS computed tomography; morphometric analysis; C-1 posterior arch; crossing screws; pediatric patients; spine

$\mathrm{P}$ EDIATRIC upper cervical instability may occur due to several congenital and acquired disorders, such as traumatic injuries, rheumatism and connective tissue disorders, Down syndrome, and os odontoideum. ${ }^{9,10,17,19}$ Surgical intervention is usually necessary to produce a stable construction. Conventional methods included posterior wiring (Brooks and Gallie techniques), Halifax clamps, C1-2 transarticular screws (Magerl technique), C-1 lateral mass screws, $\mathrm{C}-2$ pedicle screws, and C-2 translaminar screws (Wright technique). ${ }^{3,5,6,11,12,20}$ These methods are associated with a high risk of pseudarthrosis, recurrent atlantoaxial instability, and vertebral artery (VA) injury.

The C-1 posterior arch crossing screw fixation tech- nique was studied using anatomical and biomechanical evaluation. Its superiority was that it entailed little risk of injury to the neural and vascular structures as long as the implants remained intraosseous..$^{14}$ Our study was designed to evaluate the dimensions of the $\mathrm{C}-1$ posterior arch in a group of Chinese children to determine the feasibility of inserting screws using the C-1 posterior arch crossing screw fixation technique (Fig. 1). Assuming a 3.5-mm tolerance for each screw and allowing for a margin of error (minimum $0.5 \mathrm{~mm}$ ) for screw placement under direct vision, the minimum height, width, and length for screw placement would be $8 \mathrm{~mm}, 4 \mathrm{~mm}$, and $15 \mathrm{~mm}$, respectively. ${ }^{14}$ 


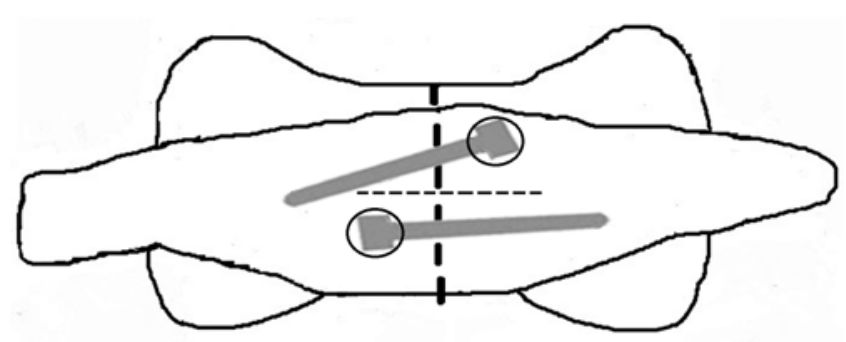

FIG. 1. Schematic drawing showing the $\mathrm{C}-1$ posterior arch crossing screw fixation technique. For posterior arch screw placement, after exposing the dorsal part of the posterior arch, the entry points were identified approximately $2 \mathrm{~mm}$ from the posterior tubercle on the opposite side; the lower point was $1 \mathrm{~mm}$ below the middle part of the posterior tubercle and parallel to the inferior rim of the C-1 arch, and the upper point was $2 \mathrm{~mm}$ higher on the other side to avoid screw interference.

\section{Methods}

The research was approved by the institutional review board of our hospital. A morphometric analysis of the C-1 posterior arch was performed in 123 pediatric patients treated at our hospital between January 2006 and December 2013. All CT scans were obtained as a result of trauma, neck pain, or any other complaint requiring cranial investigation. Exclusion criteria included congenital deformity, fracture, tumors, inflammatory disease, and previous surgery. The patients were grouped according to age (Table 1) as follows: Group 1 (1-3 years, 9 cases); Group 2 (4-6 years, 42 patients); Group 3 (7-9 years, 30 patients); Group 4 (10-12 years, 20 patients); Group 5 (13-15 years, 15 patients); and Group 6 (16-18 years, 7 patients).

All CT images of patients were taken using a 16-T CT scanner (Philips Medical Systems). The scan parameters were $120 \mathrm{kV}, 180 \mathrm{MA}, 512 \times 512$ matrix, and slice thickness $2 \mathrm{~mm}$. The height of the posterior tubercle was measured through the middle plane of the posterior tubercle on the sagittal plane. The width of the posterior arch was measured bilaterally in 3 parts on the axial plane (the posterior tubercle; the medial side of the VA groove, where the arch transforms into the VA groove; and the middle part between the posterior tubercle and the medial side of the VA groove). The length of the posterior arch was measured bilaterally from the entry point to the interior VA groove. ${ }^{14}$ Representative dimensions were defined as shown in Fig. 2, and measurements were analyzed for placement of crossing screws in the C-1 posterior arch. All measurements were obtained with a picture archiving and communication system (PACS) and were rounded to the nearest $0.01 \mathrm{~mm}$.

TABLE 1. Summary of group design in 123 pediatric patients with screw fixation of the $\mathrm{C}-1$ posterior arch

\begin{tabular}{ccccc}
\hline Group & Age $(\mathrm{yrs})$ & Male & Female & All \\
\hline 1 & $1-3$ & 5 & 4 & 9 \\
\hline 2 & $4-6$ & 26 & 16 & 42 \\
\hline 3 & $7-9$ & 22 & 8 & 30 \\
\hline 4 & $10-12$ & 14 & 6 & 20 \\
\hline 5 & $13-15$ & 13 & 2 & 15 \\
\hline 6 & $16-18$ & 7 & 0 & 7 \\
\hline
\end{tabular}

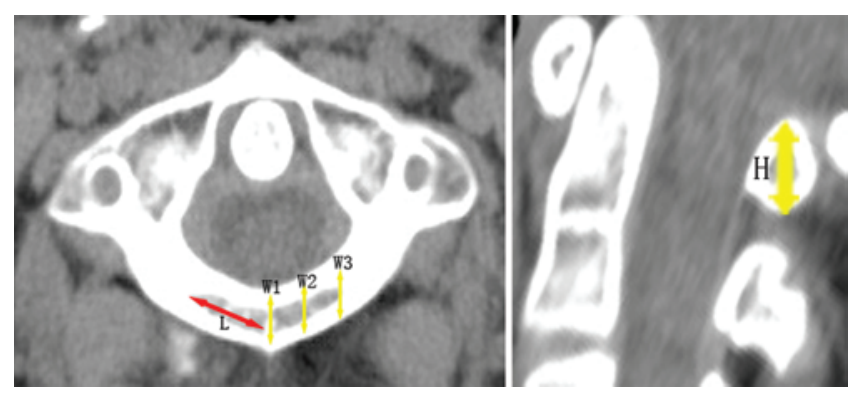

FIG. 2. Measurement of the $C-1$ posterior tubercle by using CT analysis. Left: The width $(\mathrm{W})$ of the posterior tubercle was measured bilaterally in 3 parts on the axial plane (W1, the posterior tubercle; W2, the middle part between the posterior tubercle and the medial side of the VA groove; W3, the medial side of the VA groove, where the arch transforms into the VA groove). The length (L) of the posterior arch was measured bilaterally from the entry point to the interior VA groove. Right: The height $(\mathrm{H})$ of the posterior tubercle was measured through the middle plane of the posterior tubercle on the sagittal plane. Figure is available in color online only.

Graphic representations of our data were created using an Excel spreadsheet (Microsoft Corp.), and statistical analysis was performed with SPSS (SPSS, Inc.). The mean $\pm \mathrm{SD}$ values were calculated for all parameters. An independent t-test was used to test the difference between boys and girls in the different age groups. Linear regression analysis was used to estimate the growth rate of the C-1 posterior arch. A $\mathrm{p}$ value $<0.05$ was considered statistically significant.

\section{Results}

There were 87 boys and 36 girls featured in our study. The median patient age at the time of CT scanning was 8.14 years (range 8 months -17 years). The measurements of mean posterior arch height, width, and length are shown in Table 2 and described below.

\section{Height of the Posterior Tubercle}

The mean values and SDs for the posterior tubercle height of each group are presented in Table 2. The mean height of the posterior tubercle was $6.35 \pm 1.80 \mathrm{~mm}$ (range 2.65-11.32 mm). A total of $41.5 \%(51 / 123)$ of the posterior tubercles had a height $\geq 7 \mathrm{~mm}$, and $16.3 \%(20 / 123)$ had a height $\geq 8 \mathrm{~mm}$. Insignificant differences were noted with respect to patient sex in any age group $(\mathrm{p}>0.05)$. The posterior tubercle height appeared to correlate well with age (R 0.799, p < 0.001).

\section{Width of the Posterior Arch}

The mean values and SDs for the posterior arch width of each group are presented in Table 2 . The mean width of the 3 parts of the posterior arch was as follows: Width 1 (4.48 $\pm 1.25 \mathrm{~mm}$, range $2.04-8.22 \mathrm{~mm})$; Width 2 (4.42 $\pm 0.68 \mathrm{~mm}$, range $2.55-6.12 \mathrm{~mm})$; and Width 3 (4.42 \pm $0.50 \mathrm{~mm}$, range $3.09-5.90 \mathrm{~mm})$. A total of $74.8 \%(92 / 123)$ of the posterior arches had a width $\geq 3.5 \mathrm{~mm}$, and $58.5 \%$ $(72 / 123)$ of the widths were $\geq 4 \mathrm{~mm}$. Except in Groups 3 and 5 , there were no significant differences between boys and girls in the other age groups. The posterior arch width appeared to correlate well with age (Width 1 : R $0.733, \mathrm{p}$ 
TABLE 2. Height, length, and width of $\mathrm{C}-1$ in 123 pediatric patients with screw fixation of the C-1 posterior arch*

\begin{tabular}{|c|c|c|c|c|c|c|c|c|c|}
\hline \multirow[b]{2}{*}{ Age (yrs) } & \multirow[b]{2}{*}{ Sex } & \multirow[b]{2}{*}{ Height (mm) } & \multicolumn{2}{|c|}{ Length (mm) } & \multirow[b]{2}{*}{ Width 1 (mm) } & \multicolumn{2}{|c|}{ Width $2(\mathrm{~mm})$} & \multicolumn{2}{|c|}{ Width $3(\mathrm{~mm})$} \\
\hline & & & Rt & $\mathrm{Lt}$ & & Rt & $\mathrm{Lt}$ & Rt & $\mathrm{Lt}$ \\
\hline \multirow[t]{3}{*}{$1-3$} & $\mathrm{~F}$ & $4.08 \pm 0.99$ & $11.87 \pm 1.16$ & $11.90 \pm 1.17$ & $2.82 \pm 0.44$ & $3.44 \pm 0.75$ & $3.36 \pm 0.73$ & $3.77 \pm 0.69$ & $3.85 \pm 0.57$ \\
\hline & M & $4.11 \pm 1.77$ & $11.44 \pm 4.74$ & $11.36 \pm 4.70$ & $2.72 \pm 1.21$ & $3.38 \pm 1.41$ & $3.41 \pm 1.44$ & $3.76 \pm 1.56$ & $3.88 \pm 1.62$ \\
\hline & All & $4.10 \pm 0.75$ & $11.63 \pm 1.00$ & $11.60 \pm 0.96$ & $2.77 \pm 0.47$ & $3.41 \pm 0.51$ & $3.39 \pm 0.52$ & $3.77 \pm 0.47$ & $3.87 \pm 0.43$ \\
\hline \multirow[t]{3}{*}{$4-6$} & $\mathrm{~F}$ & $5.10 \pm 0.96$ & $12.98 \pm 0.83$ & $12.86 \pm 0.86$ & $3.54 \pm 0.76$ & $3.94 \pm 0.68$ & $3.96 \pm 0.67$ & $4.19 \pm 0.42$ & $4.21 \pm 0.35$ \\
\hline & $M$ & $5.15 \pm 0.92$ & $13.57 \pm 0.96$ & $13.56 \pm 0.94$ & $3.74 \pm 0.68$ & $4.16 \pm 0.49$ & $4.12 \pm 0.51$ & $4.36 \pm 0.61$ & $4.32 \pm 0.58$ \\
\hline & All & $5.13 \pm 0.92$ & $13.34 \pm 0.95$ & $13.29 \pm 0.96$ & $3.66 \pm 0.71$ & $4.07 \pm 0.57$ & $4.06 \pm 0.58$ & $4.30 \pm 0.55$ & $4.28 \pm 0.50$ \\
\hline \multirow[t]{3}{*}{$7-9$} & $\mathrm{~F}$ & $6.15 \pm 1.24$ & $14.06 \pm 0.71 \dagger$ & $14.24 \pm 0.73 \dagger$ & $4.62 \pm 0.69$ & $4.37 \pm 0.29$ & $4.39 \pm 0.29$ & $4.21 \pm 0.37 \dagger$ & $4.18 \pm 0.35 \dagger$ \\
\hline & M & $6.40 \pm 1.46$ & $15.02 \pm 0.84 \dagger$ & $15.04 \pm 0.85 \dagger$ & $4.83 \pm 1.02$ & $4.74 \pm 0.51$ & $4.74 \pm 0.66$ & $4.61 \pm 0.41 \dagger$ & $4.63 \pm 0.36 \dagger$ \\
\hline & All & $6.34 \pm 1.39$ & $14.76 \pm 0.90$ & $14.83 \pm 0.89$ & $4.77 \pm 0.93$ & $4.64 \pm 0.49$ & $4.64 \pm 0.60$ & $4.51 \pm 0.43$ & $4.51 \pm 0.41$ \\
\hline \multirow[t]{3}{*}{$10-12$} & $\mathrm{~F}$ & $7.95 \pm 0.67$ & $15.72 \pm 0.60$ & $15.63 \pm 0.55$ & $5.71 \pm 0.45$ & $4.99 \pm 0.29$ & $4.87 \pm 0.40$ & $4.59 \pm 0.45$ & $4.55 \pm 0.35$ \\
\hline & M & $7.31 \pm 0.65$ & $15.49 \pm 0.50$ & $15.40 \pm 0.47$ & $4.78 \pm 1.00$ & $4.65 \pm 0.40$ & $4.61 \pm 0.43$ & $4.54 \pm 0.23$ & $4.53 \pm 0.28$ \\
\hline & All & $7.50 \pm 0.70$ & $15.56 \pm 0.52$ & $15.47 \pm 0.49$ & $5.06 \pm 0.97$ & $4.75 \pm 0.40$ & $4.69 \pm 0.43$ & $4.55 \pm 0.30$ & $4.53 \pm 0.29$ \\
\hline \multirow[t]{3}{*}{$13-15$} & $\mathrm{~F}$ & $9.13 \pm 2.68$ & $15.84 \pm 0.85$ & $15.99 \pm 0.18$ & $4.70 \pm 0.03 \dagger$ & $4.86 \pm 0.66$ & $4.85 \pm 0.73$ & $4.76 \pm 1.68$ & $4.66 \pm 1.47$ \\
\hline & $M$ & $8.42 \pm 1.26$ & $16.55 \pm 1.13$ & $16.47 \pm 0.91$ & $6.22 \pm 1.23 \dagger$ & $5.04 \pm 0.60$ & $5.13 \pm 0.61$ & $4.65 \pm 0.40$ & $4.75 \pm 0.34$ \\
\hline & All & $8.52 \pm 1.39$ & $16.45 \pm 1.10$ & $16.41 \pm 0.87$ & $6.02 \pm 1.25$ & $5.02 \pm 0.58$ & $5.09 \pm 0.60$ & $4.66 \pm 0.59$ & $4.74 \pm 0.51$ \\
\hline \multirow[t]{3}{*}{$16-18$} & $\mathrm{~F}$ & - & - & - & - & - & - & - & - \\
\hline & M & $8.78 \pm 1.76$ & $16.66 \pm 1.11$ & $16.59 \pm 1.16$ & $5.66 \pm 0.65$ & $4.82 \pm 0.32$ & $4.63 \pm 0.51$ & $4.69 \pm 0.25$ & $4.71 \pm 0.34$ \\
\hline & All & $8.78 \pm 1.76$ & $16.66 \pm 1.11$ & $16.59 \pm 1.16$ & $5.66 \pm 0.65$ & $4.82 \pm 0.32$ & $4.63 \pm 0.51$ & $4.69 \pm 0.25$ & $4.71 \pm 0.34$ \\
\hline
\end{tabular}

- = none.

* Values are expressed as the mean \pm SD.

$\dagger$ Significant at $p<0.05$.

$<0.001$; Width 2: R 0.602, p < 0.005; Width 3: R 0.415, p $<0.005)$.

\section{Length of the Posterior Arch}

The mean values and SDs for the posterior arch length of each group are presented in Table 2. The mean length of the posterior arch was $14.48 \pm 1.67 \mathrm{~mm}$ (range 10.25-19.06 $\mathrm{mm})$. A total of $45.9 \%(113 / 246)$ of the posterior tubercles had a length $\geq 15 \mathrm{~mm}$, and $17.5 \%$ (43/246) had a length $\geq$ $16 \mathrm{~mm}$. Except in Group 3, there were no significant differences between boys and girls in the other age groups. The posterior tubercle height appeared to correlate well with age $(\mathrm{R} 0.854, \mathrm{p}<0.001)$.

\section{Estimated Growth Rates}

The growth rates of the posterior arch (height, width, and length) were estimated using linear regression models. The growth rate of height was estimated to be $0.366 \mathrm{~mm} /$ year, and the growth rate of length was $0.361 \mathrm{~mm} / \mathrm{year}$. With respect to width, the rates were $0.237 \mathrm{~mm} /$ year at Width 1, $0.105 \mathrm{~mm} /$ year at Width 2, and $0.053 \mathrm{~mm} /$ year at Width 3 (Fig. 3).

\section{Discussion}

Surgical treatment of atlantoaxial instability can be challenging in pediatric patients. There were various fixation options discussed for $\mathrm{C} 1-2$. Wiring fixation was the first technique described to treat pediatric patients with Down syndrome. ${ }^{8,18}$ However, it was difficult to obtain solid fusion, and the procedure would increase the risk of spinal cord injury. Then the use of C1-2 transarticu- lar screws had been reported in pediatric patients with atlantoaxial instability., ${ }^{1,2}$ However, it did not provide good stability during extension and flexion because of 2-point fixation. Leonard and Wright ${ }^{16}$ reported that C-2 translaminar crossing screws could be used successfully in children. This technique has gained popularity due to the rigid fixation obtained and the low risk of injury to the VA. In 2008, Donnellan et al. ${ }^{7}$ presented a novel technique of atlantoaxial fixation in which multiaxial C-1 posterior arch screws were used. Its superiority was that it entailed little risk of injury to the neural and vascular structures as long as the implants remained intraosseous. As far as we know, though, there is no clinical evidence about this technique in the general pediatric population. Our study evaluated the dimensions of the $\mathrm{C}-1$ posterior arch in 123 Chinese children in 6 different age groups to determine the feasibility of inserting screws using the $\mathrm{C}-1$ posterior arch crossing screw fixation technique.

In this study, the mean measurement of posterior arch was height $(6.35 \pm 1.80 \mathrm{~mm})$, width (Width $1: 4.48 \pm 1.25$ $\mathrm{mm}$, Width 2: $4.42 \pm 0.68 \mathrm{~mm}$, Width $3: 4.42 \pm 0.50 \mathrm{~mm})$, and length $(14.48 \pm 1.67 \mathrm{~mm})$. Except in Groups 3 and 5 , there were no significant differences between boys and girls in other age groups. Width changed little with age, but statistically significant age-related differences were noted in height and length (Fig. 3). Christensen et al. ${ }^{4}$ found that the mean thickness of the median of the arch was $7.82 \pm$ $2.64 \mathrm{~mm}$ and the average height was $9.58 \pm 2.26 \mathrm{~mm}$ in 120 atlas vertebrae. Hong et al. ${ }^{13}$ showed that the average width of the lateral arch in 30 cases was $4.7 \pm 1 \mathrm{~mm}$. Kap$\operatorname{lan}^{15}$ found that the anterior medial side of the VA groove to the posterior tubercle was $12-16 \mathrm{~mm}$ and the outer side 

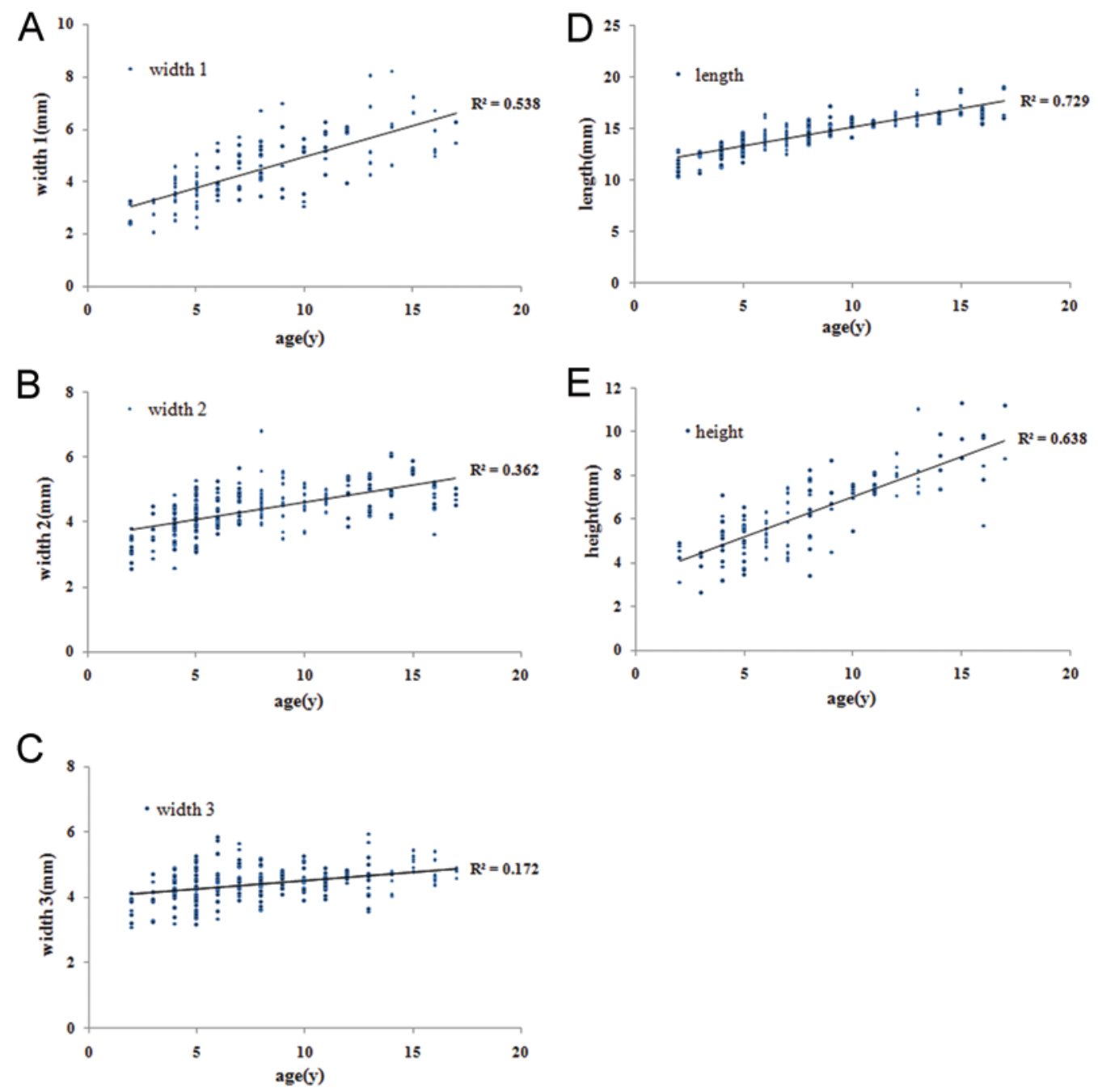

FIG. 3. Graphs demonstrating width, length, and height of the $\mathrm{C}-1$ posterior tubercle. Linear regression analysis was used to determine an annual growth rate. Figure is available in color online only.

half-distance of the arch was 22-28 mm (left, $20.7 \mathrm{~mm}$; right, $20.2 \mathrm{~mm}$ ). These results were the same as ours.

Assuming a $3.5-\mathrm{mm}$ tolerance for each screw and allowing for a margin of error (minimum $0.5 \mathrm{~mm}$ ) for screw placement under direct vision, the minimum height, width, and length for screw placement would be $8 \mathrm{~mm}, 4$ $\mathrm{mm}$, and $15 \mathrm{~mm}$, respectively. ${ }^{14}$ Our data also showed that a total of $16.3 \%(20 / 123)$ of the posterior tubercles had a height $\geq 8 \mathrm{~mm} ; 58.5 \%(72 / 123)$ had a Width $1 \geq 4 \mathrm{~mm}$; $72.8 \%(179 / 246)$ had a Width $2 \geq 4 \mathrm{~mm} ; 82.5 \%(203 / 246)$ had a Width $3 \geq 4 \mathrm{~mm}$; and $45.9 \%$ (113/246) of the posterior tubercles had a length $\geq 15 \mathrm{~mm}$. The data imply that the height of the posterior tubercle is the main restrictive factor for inserting crossing screws into $\mathrm{C}-1$ in pediatric patients. We found that $6.93 \%(7 / 101)$ of the children in Groups 1-4 and 59.1\% (13/22) of the children in Groups 5 and 6 could safely accommodate placement of C-1 posterior arch crossing screws (Fig. 4). These findings suggest that this technique may be safer and technically easier in older children.

However, there are a number of limitations with our study. First, the measurement error is inevitable. Next, our

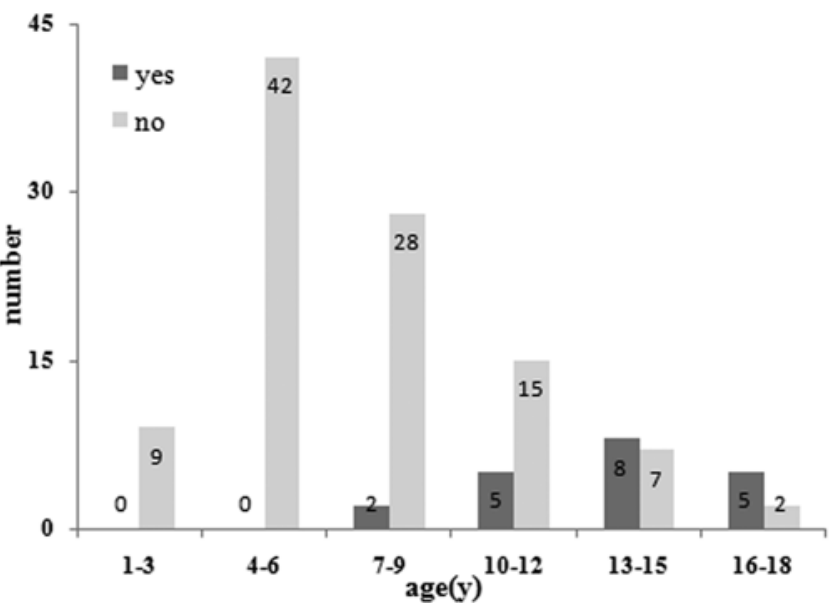

FIG. 4. Graph showing the distribution of patients whose anatomy was able to accept C-1 posterior arch crossing screws. Twenty (16.3\%) of the 123 posterior arches could accept inserted screws, and the majority of children in Groups 5 and 6 could safely accommodate placement of C-1 posterior arch crossing screws. No $=\mathrm{C}-1$ posterior arch crossing screws could not be accommodated; yes = C-1 posterior arch crossing screws could be accommodated. 
study gave less consideration to the surrounding anatomy such as the VA and others. Last, this study was merely a CT morphometric analysis, and clinical practice is essential to test the safety and effectiveness of $\mathrm{C}-1$ posterior arch crossing screws.

\section{Conclusions}

Our investigation found that use of a C-1 posterior arch crossing screw was feasible in Chinese pediatric patients, particularly in those 13 years and older. Preoperative thincut CT is essential for identifying children in whom this technique is applicable and for planning screw placement.

\section{References}

1. Anderson RC, Kan P, Gluf WM, Brockmeyer DL: Long-term maintenance of cervical alignment after occipitocervical and atlantoaxial screw fixation in young children. J Neurosurg 105 (1 Suppl):55-61, 2006

2. Brockmeyer DL, York JE, Apfelbaum RI: Anatomical suitability of C1-2 transarticular screw placement in pediatric patients. J Neurosurg 92 (1 Suppl): 7-11, 2000

3. Brooks AL, Jenkins EB: Atlanto-axial arthrodesis by the wedge compression method. J Bone Joint Surg Am 60:279_ 284, 1978

4. Christensen DM, Eastlack RK, Lynch JJ, Yaszemski MJ, Currier BL: C1 anatomy and dimensions relative to lateral mass screw placement. Spine (Phila Pa 1976) 32:844-848, 2007

5. Cybulski GR, Stone JL, Crowell RM, Rifai MH, Gandhi Y, Glick R: Use of Halifax interlaminar clamps for posterior C1-C2 arthrodesis. Neurosurgery 22:429-431, 1988

6. Dickman CA, Sonntag VKH: Posterior C1-C2 transarticular screw fixation for atlantoaxial arthrodesis. Neurosurgery 43:275-281, 1998

7. Donnellan MB, Sergides IG, Sears WR: Atlantoaxial stabilization using multiaxial C-1 posterior arch screws. J Neurosurg Spine 9:522-527, 2008

8. Doyle JS, Lauerman WC, Wood KB, Krause DR: Complications and long-term outcome of upper cervical spine arthrodesis in patients with Down syndrome. Spine (Phila Pa 1976) 21:1223-1231, 1996

9. Dyck P: Os odontoideum in children: neurological manifestations and surgical management. Neurosurgery 2:93-99, 1978

10. Foster HE, Cairns RA, Burnell RH, Malleson PN, Roberton
DM, Tredwell SJ, et al: Atlantoaxial subluxation in children with seronegative enthesopathy and arthropathy syndrome: 2 case reports and a review of the literature. J Rheumatol 22:548-551, 1995

11. Goel A, Laheri V: Plate and screw fixation for atlanto-axial subluxation. Acta Neurochir (Wien) 129:47-53, 1994

12. Harms J, Melcher RP: Posterior C1-C2 fusion with polyaxial screw and rod fixation. Spine (Phila Pa 1976) 26:24672471,2001

13. Hong X, Dong Y, Yunbing C, Qingshui Y, Shizheng Z, Jingfa L: Posterior screw placement on the lateral mass of atlas: an anatomic study. Spine (Phila Pa 1976) 29:500-503, 2004

14. Jin GX, Wang H, Li L, Cui SQ, Duan JZ: C1 posterior arch crossing screw fixation for atlantoaxial joint instability. Spine (Phila Pa 1976) 38:E1397-E1404, 2013

15. Kaplan EB: Surgical Approaches to the Neck, Cervical Spine and Upper Extremity. Philadelphia: Saunders, 1967, pp 244-245

16. Leonard JR, Wright NM: Pediatric atlantoaxial fixation with bilateral, crossing C-2 translaminar screws. Technical note. J Neurosurg 104 (1 Suppl):59-63, 2006

17. Orenstein JB, Klein BL, Gotschall CS, Ochsenschlager DW, Klatzko MD, Eichelberger MR: Age and outcome in pediatric cervical spine injury: 11-year experience. Pediatr Emerg Care 10:132-137, 1994

18. Segal LS, Drummond DS, Zanotti RM, Ecker ML, Mubarak SJ: Complications of posterior arthrodesis of the cervical spine in patients who have Down syndrome. J Bone Joint Surg Am 73:1547-1554, 1991

19. Tredwell SJ, Newman DE, Lockitch G: Instability of the upper cervical spine in Down syndrome. J Pediatr Orthop 10:602-606, 1990

20. Wright NM: Posterior C2 fixation using bilateral, crossing C2 laminar screws: case series and technical note. J Spinal Disord Tech 17:158-162, 2004

\section{Author Contributions}

Conception and design: Xiang. Acquisition of data: Xiang, Lou. Analysis and interpretation of data: Xiang, Wang, Fang, Tian. Reviewed submitted version of manuscript: Xu. Approved the final version of the manuscript on behalf of all authors: $\mathrm{Xu}$.

\section{Correspondence}

Hua-Zi Xu, Zhejiang Spine Research Center, Department of Orthopaedic Surgery, Second Affiliated Hospital of Wenzhou Medical University, 109 Xueyuanxi Rd., Wenzhou 325000, China.email: spinexu@163.com. 